\title{
X-Ray Loupes - The answer to your endodontic misery
}

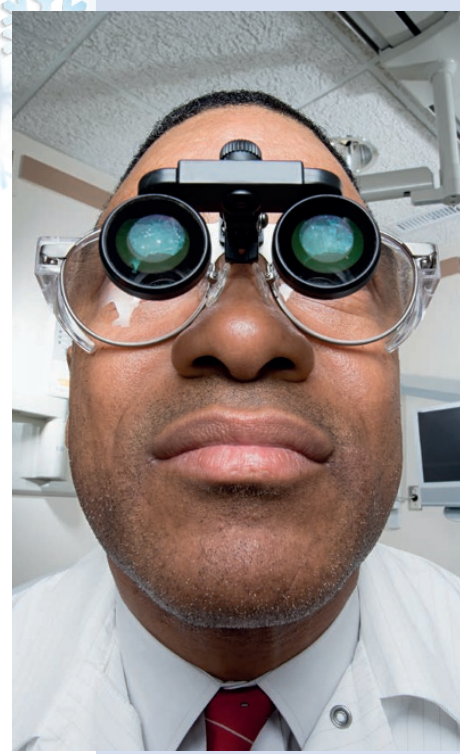

If endodontics is your passion, then today is your lucky day. The Loupers Company, a renowned loupes company, has recently published its study on the effectiveness of its new product X-Ray Loupes. The loupes, the first of their kind in the world, offer dentists and endodontists alike the ability to scan endodontic sites while operating.

In the research collaboration with the Yorkshire Centre for Dentistry, it was found that usage of the $\mathrm{X}$-Ray Loupes significantly reduced operative errors by $70 \%$. These errors included minimising the likeliness of creating ledges, instrument fractures and perforations.

Thanks to its efficacious beaming ray, there is no need to stop your endodontic treatment midway for countless radiographs as X-Ray Loupes allow you to visualise through bones, teeth and soft tissues. This halves the treatment time which is good news for you and busy patients.

The company has also addressed concerns about radiation exposure. The loupes are designed to be lined with lead to protect its user. Our advanced digital technology has also allowed for the patient exposure to be reduced significantly. No hassle with IR(ME) $\mathrm{R}$ on this one.
For those requiring the X-ray images to be extracted for recordkeeping, the loupes also feature new radio frequency identification device (RFID) technology.

With the click of a button on the side of its frame, the X-ray images will be downloaded into software on your computer in no time. No need to worry about endodontic working lengths, as the loupes also allow for calibration or measurement to be made during endodontic treatments using augmented reality (AR) technology.

In this Christmas season, there is no better gift for another dentist than X-Ray Loupes.

Get your own pair of X-Ray Loupes now at www.thelouperscompany.co.uk/xray.

By Othman Zuhir

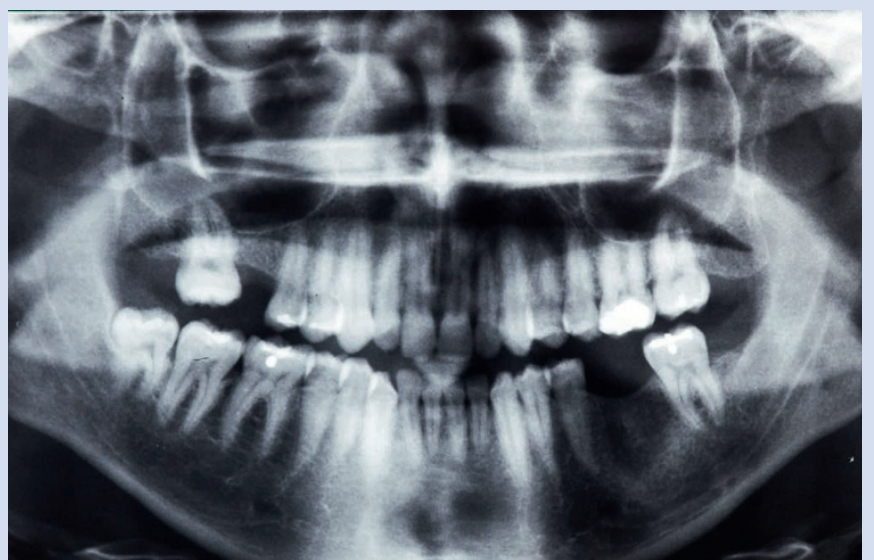

\section{Dentistry is coming home (first published in June 2018)}

FIDA (Fédération Internationale de Dentistry Association) has released a series of limited edition souvenir dentures, braces and crowns to take advantage of this Summer's world cup fever.

Show your support for the England team with these limited edition braces. They promise a solid back four molars and one great central incisor. The rest may be fairly average and will crumble under the pressure of bruxing.

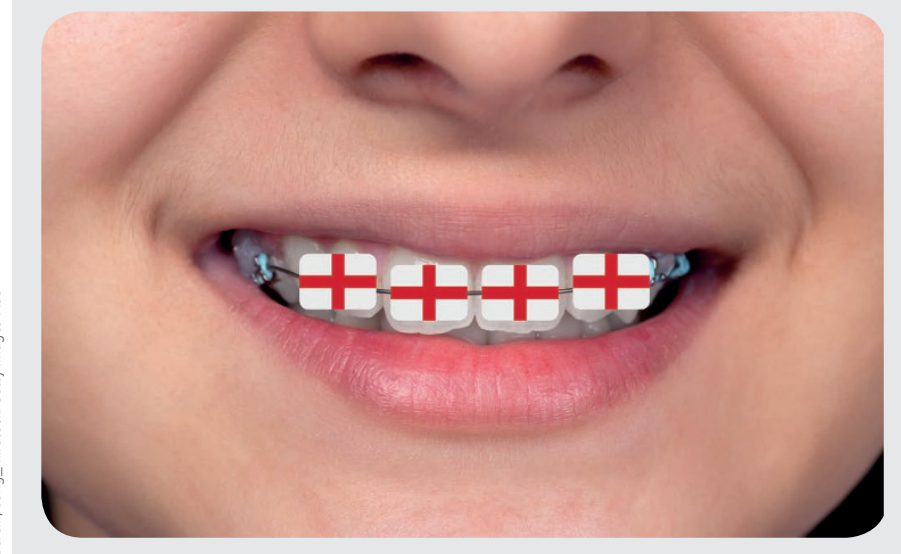

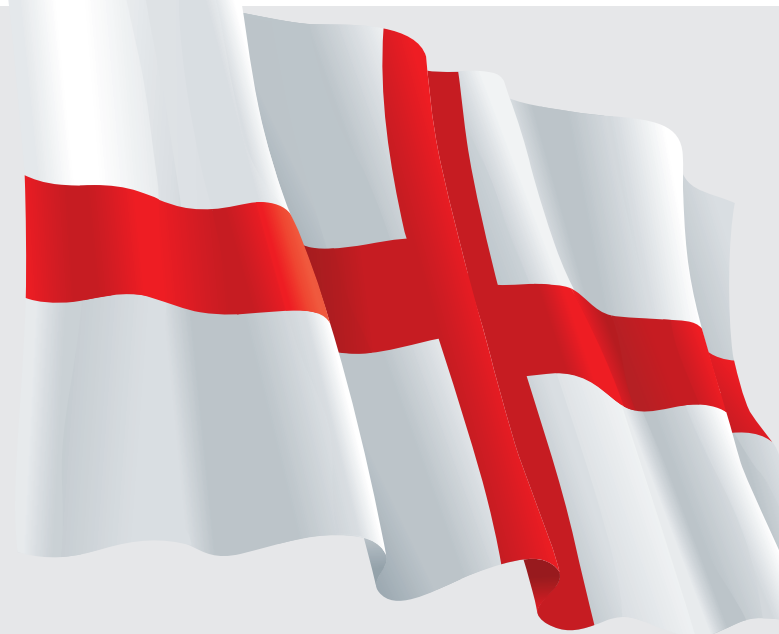

Allez les Bleus!

Get behind France with our

premium braces. Expect perfectly straight teeth. You won't be disappointed.

Get $50 \%$ off our Team Germany range. You may have great expectations for these normally great dentures, however, this batch is very ineffective. Probably won't last a week.

Unfortunately, due to manufacturing issues, Team Italy, Netherlands and USA items will not be available. 